\title{
Risk Factors in Patients with Intrauterine Fetal Death at Tertiary Referral Centre
}

\author{
Sinha $\mathrm{K}^{1}$, Pandey $\mathrm{S}^{2}$
}

Background: Among various community health indicators available for measurement of quality and impact of health services in developing countries, perinatal mortality accounts one of the top most single indicators even today. Documentation and evaluation of the etiology and the associated risk factors for stillbirth is required in order to decrease the fetal mortality rate and to devise plan in maternal health sector. Objective: To find out common risk factors in patient and its association with intrauterine fetal death. Methods: A hospital based cross-sectional study carried out in the Department of OBSGYN, Nepalgunj Medical College, Kohalpur from Jan 2018 to September 2019.Cases of multiple pregnancies, intrapartum death and fetal death diagnosed before $28^{\text {th }}$ weeks of gestation were excluded. After exclusion, 65 cases of intrauterine fetal death were studied. Results: Majority (78.4\%) of the patients with IUFD belonged to the reproductive age group(20-35yrs) and(15.4\%)belong to $<19 y r s(p=0.008)$ associated with illiteracy (84.6\%). More than half (58.5\%) had at least one ANC visit and were primigravida (17\%) with preterm (63.07\%).Hypertensive disorder was the commonest obstetric complication in these mothers (36.92\%) followed by unexplained(26.15\%), anaemia (18.46\%), PROM (15.4\%), APH (13.8\%). Most of the babies were low birth weight (63.69\%) and majority were males (63.1\%). Conclusion: Majority of the risk factors found in the present study were preventable. Stillbirth rate can be reduced by proper management of these risk factors during antenatal care and intrapartum care.

\section{Keywords: Antenatal care, Intrauterine fetal death, PIH, Risk factors, Stillbirth}

1. Dr. Kavita Sinha

2. Dr. Subhash Pandey

Address for correspondence:

Dr. Kavita Sinha

Assistant Professor

Department of Obstetrics \& Gynaecology

Nepalgunj Medical College Teaching Hospital

Kohalpur, Banke, Nepal

Email: ksinhapandey@gmail.com

\section{INTRODUCTION}

Fetal death is traumatic experience for the mother in particular and for the family as a whole and remains a challenge for obstetrician. According to World Health Organization (WHO), Intrauterine Fetal Death (IUFD) is defined as "Death prior to complete expulsion or extraction from the mother of a product of human conception irrespective of the duration of pregnancy and which is not an induced termination of pregnancy"1. However, conventionally and also in our country, fetal demise prior to 28 weeks of gestation is managed as abortion in a manner different from fetal demise post 28 weeks of gestation ${ }^{2}$.

Worldwide 3.3 million stillbirths are reported annually, $97 \%$ occurring in developing countries. Only $4 \%$ of cases are registered in developing countries where under reporting is common. It is believed that an additional 1-2 million of unrecorded stillbirths occur in these developing countries ${ }^{3}$. It is a heartbreaking and tragic event which occurs in $1 \%$ of all pregnancies globally4. Whereas in Nepal, according to NDHS (2016) it accounts for $1.5 \%$ of all pregnancies ${ }^{3}$. Perinatal mortality rate in Nepal is 31 deaths per 1000 births, where stillbirth rate of 15.3 per 1000 births and early neonatal death rate of 15.7 per 1000 births $^{5}$.

Risk factors for intrauterine fetal death (IUFD) include general and specific categories. General includes socio-demographic factors such as place of living, occupation and level of education etc. Specific factors include fetal, maternal,umbilical cord and placental factors. IUFD risk increases by 4 times with pregnancy at an early age i.e. age of 16 years and less ${ }^{6}$. There are intensified demands on medical, political and epidemiological ground for proper determination and classification of causes of fetal death in order to formulate the preventive policies and protocols for the reduction of IUFD rate?

Fetal death case be diagnosed by ultrasound, whereas other modalities like cardio topography and fetal scalp electrodes can be misleading as can record maternal pulse rate even when the fetus is dead. So, IUFD is always confirmed by ultrasonography ${ }^{8}$. In Nepal, the government provides free antenatal check-ups through its public health facilities and has a standard protocol for antenatal check-ups ${ }^{9}$. Nevertheless, only two-thirds of women in the country visit for antenatal check-ups from a skilled healthcare provider, and only $61 \%$ of women receive adequate antenatal check-ups ${ }^{10}$. In our study we attempted to identify risk factors associated with IUFD.

\section{MATERIAL AND METHODS}

Hospital based cross-sectional study was conducted in the Department of obstetrics and gynaecology, Nepalgunj Medical College Teaching Hospital, Kohalpur from January 2018 to September 2019. Cases of multiple pregnancies, intrapartum death and fetal death diagnosed before $28^{\text {th }}$ weeks of gestation were excluded. 
Sinha et al.: Risk Factors in Patients with Intrauterine Fetal Death at Tertiary Referral Centre

\section{SAMPLE SIZE CALCULATIONS}

The prevalence of IUFD, $p=2.13 \%$ according to Tamrakar SR2 Tabulated value of $\mathrm{z}$ at $95 \% \mathrm{Cl}=1.96$

Allowable error, e $=5 \%(0.05)$

Sample size $(n) \quad=z^{2} p(1-p) / e^{2}$

$=(1.96)^{2} \times 0.049 \times(1-0.049) /(0.05) 2$

$=31.57$

$=32$

So, the required sample size of the study was 32 , to decrease biasness sample size increased by twice.

Participants who meet inclusion criteria obtained from Gynae opd or labour room and willing to give consent for participation in study, enrolled. Pregnant women diagnosed with intrauterine fetal death after 28 weeks of gestation, confirmed by ultrasonography prior to the onset of labour (Ante partum) were included in the study. Data collected in structured proforma were entered in Microsoft Excel, compared by using chi-square test and statistical analysis were done with SPSS version 20.

Total number of admission in labour room during the study period was 3975 of which 3644 were delivered and 65 were stillbirth. The rate of stillbirth was 23.87 per 1000 birth. Relation between $<19 y$ rs age and reproductive age group (20$35 y r s) P$ value found 0.008 ,statistically significant associated with lower education level $(84.6 \%$,).More than half $(58.5 \%)$ had at least one ANC visit and were preterm (63.07\%) with primigravida, (17\%). Hypertensive disorder was the commonest obstetric complication in these mothers (36.92\%) followed by unexplained (26.15\%), anaemia (18.46\%), PROM (15.4\%), APH (13.8\%). Most of the babies were low birth weight (63.69\%) and majority were males (63.1\%).

\begin{tabular}{|c|c|c|c|}
\hline Factors & Complications & Number & Percentage \\
\hline \multirow{6}{*}{ Maternal } & Anaemia & 12 & 18.46 \\
\hline & HTN Disorder & 24 & 36.92 \\
\hline & PROM & 10 & 15.4 \\
\hline & Maternal infections & 06 & 9.23 \\
\hline & Abdominal trauma & 02 & 3.08 \\
\hline & Gestational Diabetes & 1 & 1.54 \\
\hline \multirow{2}{*}{ Fetal } & RH Isoimmunization & 5 & 7.69 \\
\hline & Congenital malformation & 2 & 3.08 \\
\hline \multirow{4}{*}{ Placental } & Placenta Praevia & 6 & 9.23 \\
\hline & Abruptio & 3 & 4.07 \\
\hline & IUGR & 2 & 3.08 \\
\hline & Post term pregnancy & 4 & 6.15 \\
\hline \multirow[t]{4}{*}{ Cord factor } & & 08 & 12.4 \\
\hline & Nuchal cord & 02 & 3.1 \\
\hline & Cord prolapse & 02 & 3.1 \\
\hline & True knot & 04 & 6.2 \\
\hline Unexplained & & 17 & 26.15 \\
\hline
\end{tabular}

Table l: Distribution of Medical and obstetrics risk factors for IUFD: Multiple factors were seen in single participant, so number increased to 110.

\begin{tabular}{|c|c|c|c|}
\hline Risk factors & Number & Percentage (\%) & $p$-value \\
\hline \multicolumn{4}{|l|}{ Age } \\
\hline \multirow{2}{*}{$\begin{array}{c}<19 y r s \\
>20-35 y r s \\
>20-35 y r s \\
>35 y r s\end{array}$} & $\begin{array}{l}10 \\
51\end{array}$ & $\begin{array}{l}15.4 \% \\
78.4 \%\end{array}$ & 0.008 \\
\hline & $\begin{array}{c}51 \\
4\end{array}$ & $\begin{array}{c}78.4 \% \\
6.2 \%\end{array}$ & 0.000 \\
\hline \multicolumn{3}{|l|}{ Education } & \multirow{3}{*}{0.001} \\
\hline \multirow{2}{*}{$\begin{array}{l}\text { Literate } \\
\text { Illiterate }\end{array}$} & 55 & 84.6 & \\
\hline & 10 & 15.3 & \\
\hline Gestation age & & & \multirow[b]{2}{*}{0.035} \\
\hline $\begin{array}{l}\text { 28-37 weeks } \\
37 \text { weeks }\end{array}$ & $\begin{array}{l}41 \\
24\end{array}$ & $\begin{array}{l}63.07 \\
36.92\end{array}$ & \\
\hline \multicolumn{3}{|l|}{ Gravidity } & \multirow{3}{*}{0.264} \\
\hline \multirow{2}{*}{$\begin{array}{l}\text { Primi } \\
\text { Multi }\end{array}$} & 37 & 56.92 & \\
\hline & 28 & 43.07 & \\
\hline Anc visit & & & \multirow{3}{*}{0.172} \\
\hline \multirow{2}{*}{$\begin{array}{l}\text { Yes } \\
\text { No }\end{array}$} & 38 & 58.46 & \\
\hline & 27 & 41.54 & \\
\hline $\begin{array}{l}H T N(B P>140 / 90, \text { at } \\
\text { measured on } 2 \text { occa }\end{array}$ & & & \multirow{3}{*}{0.035} \\
\hline \multirow{2}{*}{$\begin{array}{l}\text { Yes } \\
\text { No }\end{array}$} & 24 & 36.9 & \\
\hline & 41 & 63.07 & \\
\hline
\end{tabular}

Table II : Association between the risk factors and IUFD (Maternal factor)

\begin{tabular}{|c|c|c|c|}
\hline Risk factor & Number(n) & Percentage(\%) & p-value \\
\hline Weight & & & \\
\hline LBW & 44 & 67.69 & \multirow{2}{*}{0.004} \\
\hline Normal & 21 & 32.30 & \\
\hline Sex & & & \multirow{2}{*}{0.035} \\
\hline Male & 41 & 63.07 & \\
\hline Female & 24 & 36.93 & \\
\cline { 1 - 3 }
\end{tabular}

Table III: Association between the risk factors and IUFD (fetal factor)

\section{DISCUSSION}

Death of a fetus is a distress to the family as well as to the obstetrician. Despite the advances in diagnostic and therapeutic modalities, stillbirth rates in developing countries are still high. Hence, proper documentation and evaluation of the risk factors will be very helpful in management aspect as well as advocating plan in maternal health sector. In our study, relation between $<19 y$ rs age and reproductive age group (20-35yrs) statistically significant which is comparable to the studies conducted by Mathuriya et $\mathrm{al}^{11}$, Patel et al ${ }^{12}$. Among different risk factors for IUFD, PIH, anaemia and PROM, $A P H, L B W$ were found in majority. Similar observation were reported by other studies too ${ }^{12,13,14}$. PIH cases were more likely to have placental insufficiency with high risk for fetal death. Timely interventions can reduce complications like abruption, IUGR and Stillbirth. Iron preparation are free of cost from 
government supply to pregnant ladies, Iron deficiency anaemia still accounts comparable to study conducted by Choudhary $A$ and Gupta $\mathrm{V}^{13}$. Deworming and consumption of nutritious diet during pregnancy is most. Majority (63.69\%) of stillbirth babies belonged to LBW as compared to Mathuriya et $\mathrm{al}^{11}$.

\section{CONCLUSION}

Illiteracy and no antenatal care are the predisposing factors for IUFD. Majority of risk factor for intrauterine fetal death like hypertension, placental abruption and anaemia will be preventable with timely ANC. Early detection of high risk pregnancy and timely referral to equipped centre will definitely rescue IUFD ratio. Health education and emphasis on institutional delivery under supervision of skilled personnel needs to be propagated in the community aggressively. This will help in reducing a number of preventable fetal deaths and huge loss of our national assets.

\section{ACKNOWLEDGEMENT}

I would like to thank Dr Pradip Mishra for kind support during statistical analysis.

\section{LIMITATIONS OF THE STUDY}

1. This is a single hospital based study, data retained may not be applicable to general population, need multicentre studies to draw valid interferences.

2. Due to technical and financial limitations, examinations such as autopsy, cytological studies of fetal tissues and placental histopathology were not done.

\section{REFERENCES}

1. World health organization. Neonatal and perinatal mortality: country, regional and global estimation. Geneva: WHO; 2006. p. 6.

2. Tamrakar SR, Chawla CD. Intrauterine foetal death and its probable causes: Two year experience in Dhulikhel hospitalKathmandu university hospital. Kathmandu Univ med J 2012; 10 (4) : 44-8.

3. Malik R, Khan NR, Arif A, Ayub S, Perveen S. Common risk factors in patients with intrauterine fetal death. J Postgrad Med Inst 2016;30(4):337-41.

4. Murray J, Callan VJ. Predicting adjustment to perinatal death. $\mathrm{Br}$ J Med Psycho 1988;61(3):237-44.

5. Government of Nepal. Nepal demographic and health survey 2016. Kathmandu: Ministry of health; 2017.p.144.

6. Conde-Aqudelo A, Beliazan JM, Diaz-Rossello JL. Epidemiology of fetal death in latinAmerica.ActaObstetgynecolScand 2000; 79:371-8.

7. Korteweg, FJ. Fetal death: classification and diagnostic work-up. FleuriscaKorteweg: University of Groningen; 2010.p. 24,179.

8. Kean L. Intrauterine fetal death. Current Obstetrics Gynecology 2016;2:199-205.

9. Government of Nepal. Aamasurakshyakaryakram 2009. Kathmandu: Ministry of health and population; 2009. p. 2

10. Government of Nepal. Nepal multiple indicator cluster survey 2014. Kathmandu: Central bureau of statistics; 2015.
11. Mathuriya G, Bunkar N. Evaluation of intrauterine foetal death at tertiary care center. Int J Med Sci Res Prac 2015;2(3):139-42.

12. Patel $S$, Thaker $R$, Shah $P$, Majumber $S$. Study of causes and complications of intra uterine fetal death (IUFD). Int J ReprodContraceptObstetGynecol 2014;3(4):931-5.

13. Choudhary A and Gupta V. Epidemiology of intrauterine fetal deaths: a study in tertiary referral centre in Uttarakhand. IOSRJDMS 2014;3(13):3-6.

14. Safarzadeh A, Ghaedniajahromi M, Rigi F, Massori N. Intra uterine fetal death and some related factors: A silent tragedy in Southeastern Iran. J Pain Relief 2014;3(1):1-3. 